Case Report

\title{
Transient Phenomenon in Polymer-Dispersed Liquid Crystals
}

H. Hakemi ${ }^{1,}{ }^{*}$, M. Khenkin ${ }^{2}$, R. Tamari $^{2}$, D. Gal-Fuss ${ }^{2}$

1. Plastic Liquid Crystal Technology, Via Lambro 80, 20846 Macherio (MB), Italy; E-Mail: hassanalihakemi@gmail.com

2. Gauzy Ltd, R\&D Division, 14th Ha'Thiya Street, Unit 203/204, Tel-Aviv, 68169, Israel; E-Mails: michal.khenkin@gauzy.com; rimon.tamari@gauzy.com; dana@gauzy.com

* Correspondence: H. Hakemi; E-Mail: hassanalihakemi@gmail.com

Academic Editor: Hossein Hosseinkhani

Recent Progress in Materials

2020, volume 2 , issue 1

doi:10.21926/rpm.2001006
Received: December 10, 2019

Accepted: February 24, 2020

Published: March 05, 2020

\begin{abstract}
In the present study, we report the experimental results related to the transient phenomenon, i.e., the time-dependent changes in the electro-optical properties of as-made polymer-dispersed liquid crystal (PDLC) films prepared by the UV-curing phase-separation method. This phenomenon occurs explicitly via polymer-induced phase separation when the matrix curing is not complete, some liquid crystal plasticized in the matrix, and some uncured pre-polymer components remain in the liquid crystal droplets. The outcome is the time-dependent changes in the electro-optical properties of as-made PDLC devices. Here, we provide the experimental results of Transient Phenomenon in a UV cured PDLC film and report on variations in some electro-optical parameters with time.
\end{abstract}

\section{Keywords}

Transient phenomenon; phase separation; PDLC; UV curing; electro-optical properties

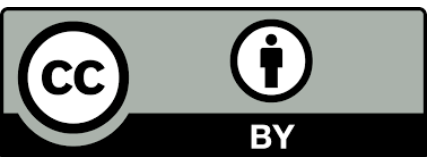

(C) 2020 by the author. This is an open access article distributed under the conditions of the Creative Commons by Attribution License, which permits unrestricted use, distribution, and reproduction in any medium or format, provided the original work is correctly cited. 


\section{Introduction}

In the past three decades, polymer-dispersed liquid crystal (PDLC) technology has attracted considerable interest in academic research, industrial research and development, and manufacturing and commercialization of PDLC films and glass products. A PDLC is a generic name for a particular two-phase composite system consisting of a dispersion of liquid crystal (LC) microdroplets in a polymer matrix that can be used in large-area electrically switchable films, shutters, and windows.

The main interest in industrial research and development of plastic LC technology was based on the premise of stabilizing LCs through their dispersion in a polymer matrix for manufacturing largearea flexible liquid crystal display (LCD) devices. This premise has resulted in the emergence of new technologies, among which the PDLC technology has been the subject of considerable industrial interest and development in the past decades. However, since its development, this technology has instead been employed mainly in commercial applications involving large-area "electrically switchable" films and windows.

Since its development in the late 1980s, despite consistent progress in basic research, the industrial evolution of the PDLC technology has witnessed cycles of setbacks and advancements. J. L. Fergason obtained the first patent on micro-emulsion (ME) technology in 1984 [1]. He eventually licensed the use of his invention to Raychem Corporation (USA) exclusively. In the late 1980s, Raychem begun commercializing this technology by forming a small start-up companyTaliq Corporation - to industrialize the PDLC switchable window and flexible display products under the "NCAP" (Nematic Curvilinear Aligned Phase) trade-mark.

Independently, in the late 1980s, Doane et al. at the Kent State University (USA) patented the "PDLC" technology developed via the phase separation (PS) approach [2]. The PS approach allows the use of a wide range of UV-curable and epoxy pre-polymers and thermoplastic polymers for PDLC processing. Eventually, due to limitations in working with ME, the PS methods began to be extensively used in both academic research and industrial development of PDLC devices.

Scientific knowledge of PDLC technology significantly increased in the past decades. Extensive academic studies have been conducted on almost all aspects of this technology, covering the chemistry and physics of PDLC materials, formulations, process parameters, and their electrooptical properties. Specifically, numerous studies have focused on PDLC materials and process parameters [3-17]. However, at the industrial level, there are other parameters of importance, including the "transient phenomenon," i.e., the time-dependent changes in the electro-optical properties of as-made PDLC films. This phenomenon is observed during natural aging within a few weeks of film preparation and is important in manufacturing, quality control, certification, and delivery of commercial products. To the best of our knowledge, no scientific study has analyzed the transient phenomenon.

The transient phenomenon occurs only in PDLC films prepared by PS methods, which is a thermodynamic approach, and the creation of LC droplets is the outcome of opposing parameters of PS and polymer curing kinetics. As the curing of the polymer matrix is not usually complete in the PDLC films immediately after fabrication, some portions of LC are plasticized in the matrix and some quantity of the pre-polymer remains in the LC droplets. The preferential solubility of certain LC components in the polymer matrix and a significant amount of uncured pre-polymer have been reported to be the cause of substantial changes in the performances of PDLC films [18]. 
Material parameters, such as the chemical and physical properties of the LCs and pre-polymer, including concentration, viscosity, refractive index, and transition temperature, as well as process parameters, including the curing temperature, UV intensity, and sample thickness have a significant effect on the electro-optical properties of PDLC films [19].

Consequently, the diffusion of the LCS and pre-polymer across the droplet boundaries and matrix plasticization by LCs are time-dependent and cause temporal variations in the electrooptical properties of as-made PDLC. The stabilization of these properties depends on several material and process parameters, and this requires experimental verification. It is important to note that the transient phenomenon and stabilization of PDLC electro-optical properties depend on many complex material and process parameters, and the understanding of the dependence requires systematic experimental verifications.

The present work is a part of our systematic study of the transient phenomenon, and we focus on the preliminary results of the time dependency of optical transmissions, operating voltages, and response times of as-made PDLC films with two types of LCs and at two UV curing energies. Further, owing to the lack of relevant information on this phenomenon in the literature, a full analysis of the present results will be the subject of our future work.

\section{Experimental}

\subsection{Materials and Preparation}

The main materials utilized in this study were a eutectic LC mixture P025 (Hebei Pharmaceutical), the UV-curable pre-polymer NOA65 resin (Norland Optical Adhesives), photoinitiator Irgacure-819 (BASF), $25 \mu \mathrm{m}$ plastic micro-spacers Microsphere (Sekisui Chemical), and $175-\mathrm{mm}$-thick $100 \mathrm{~W} / \mathrm{cm}^{2}$ indium tin oxide (ITO)-polyethylene terephthalate (PET) film supports (Eastman Chemicals). The utilized PDLC formulations are as follows:

- P025-40: 40\% P025, 59\% NOA65, 0.5\% Irgacure-819, and 0.5\% Micro-sphere.

- P025-49.5: 49.5\% P025, 49.5\% NOA65, 0.5\% Irgacure-819, and 0.5\% Micro-sphere.

All flexible PDLC formulations were prepared according to the standard procedure: all components were weighed, inserted into a vial, and mixed for $4 \mathrm{~h}$ at a constant temperature of $45^{\circ} \mathrm{C}$. The uncured homogeneous mixture consisting of P025 and the NOA65 pre-polymer, photoinitiator, and micro-spacer was coated and laminated in situ between two ITO-PET film supports by using a laboratory-scale hand coater. The uncured PDLC sheet was then placed on a custommade conveyor belt and cured using a UV lamp at $31.7 \mathrm{~mW} / \mathrm{cm}^{2}$ intensity and $0.50,0.30$, and 0.15 $\mathrm{m} / \mathrm{min}$ line speeds, which correspond to 380,634 , and $1268 \mathrm{~mJ} / \mathrm{cm}^{2}$ UV curing energies, respectively. In Table 1, we list the physical, optical, and thermal properties of the P025 LC mixture.

Table 1 Physical and optical properties of P025.

\begin{tabular}{|l|l|l|l|l|l|}
\hline $\begin{array}{l}\mathbf{C} \rightarrow \mathbf{N} \\
\left({ }^{\circ} \mathrm{C}\right)\end{array}$ & $\begin{array}{l}\mathbf{N} \rightarrow \mathbf{I} \\
\left({ }^{\circ} \mathrm{C}\right)\end{array}$ & $\begin{array}{l}\text { Viscosity } \\
\left(\mathrm{mpa}, 20^{\circ} \mathrm{C}\right)\end{array}$ & $\mathbf{\Delta n}$ & $\begin{array}{l}\mathbf{n}_{\mathbf{o}}(589 \mathrm{~nm}, \\
\left.20^{\circ} \mathrm{C}\right)\end{array}$ & $\begin{array}{l}\mathbf{n}_{\mathrm{e}}(589 \mathrm{~nm}, \\
\left.20^{\circ} \mathrm{C}\right)\end{array}$ \\
\hline-10 & 94 & 60 & 0.250 & 1.521 & 1.771 \\
\hline
\end{tabular}




\subsection{Methods \& Measurements}

The electro-optical properties of PDLC films within 14 days after fabrication were determined using a custom-made electro-optical system (EOS). The haze values were measured using a BYK Hazegard-I hazemeter. The PDLC morphologies were determined by using a Quanta-200-FEG scanning electron microscope (SEM) on days 0,7 , and 14 after fabrication. The thermal properties of the uncured mixture and the cured PDLC films were determined by differential scanning calorimetry (DSC) by using a Perkin Elmer DSC-6000. The range of measurement errors for the hazemeter is \pm 0.26 and, for the EOS, is less than $1 \%$. The fluctuations in experimental data points are mainly due to the instrument recalibration. In Table 2, we tabulated the average LC microdroplet dimensions ( $\angle D>$ ) of the PDLC films as a function of the UV curing energy at $40 \%$ and 49.5\% concentrations. In Figure 1, we present examples of SEM micrographs of P025-40 PDLC films as a function of the UV curing energy.

Table 2 SEM morphologies as a function of UV curing energy.

\begin{tabular}{|c|c|c|}
\hline & P025-40 & P025-49.5 \\
\hline$E_{\text {UV }}\left(\mathrm{mJ} / \mathrm{cm}^{2}\right)$ & $<D>(\mathrm{mm})$ & $<\mathrm{D}\rangle(\mathrm{mm})$ \\
\hline 380 & 0.33 & 0.63 \\
\hline 634 & 0.61 & 0.58 \\
\hline 1268 & 0.71 & 0.52 \\
\hline
\end{tabular}

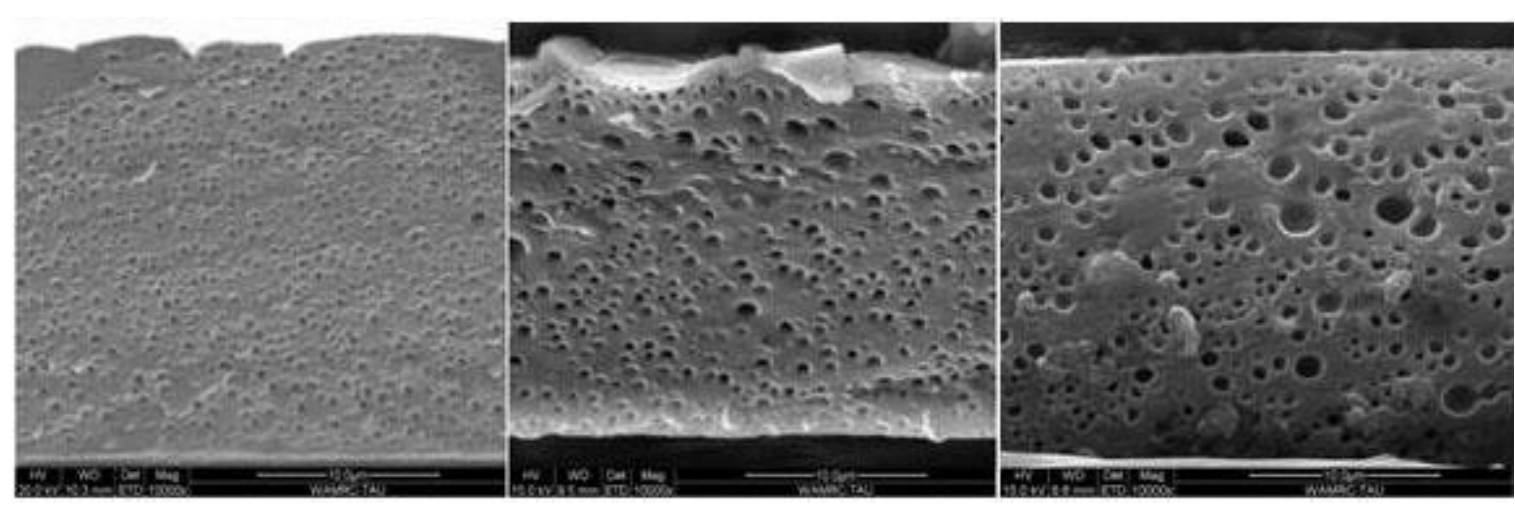

Figure 1 SEM morphologies of P025-40 films at UV energies of 380 (left), 634 (center) and 1268 (right) $\mathrm{mJ} / \mathrm{cm}^{2}$.

\section{Results and Discussions}

Although the complete analysis of the experimental results is beyond the scope of the present study and is the subject of our ongoing systematic study, herein, we report the preliminary results of the transient phenomenon in relation to the haze; specular optical transmissions Tmax (on-state) and $T$ min (off-state); operating voltages $\mathrm{V}_{10}$ (threshold voltage) and $\mathrm{V}_{90}$ (saturation voltage) and switching times $\tau_{\text {on }}$ (rise time) and $\tau_{\text {off }}$ (decay time) for the two types of P025-PDLC films. The results show the existence of the transient phenomenon in the PDLC films after fabrication: i.e., most electro-optical parameters tend to undergo time-dependent variations under natural laboratory aging conditions, before stabilization. These experimental results are discussed in detail in the following sections. 


\subsection{Transient Phenomenon in Terms of Optical Transmission}

The transient phenomenon in terms of haze in P025-40 and P025-49.5 PDLC films is presented in Figure 2 for 380,634, and $1268 \mathrm{~mJ} / \mathrm{cm}^{2}$ UV curing energies. The experimental data in Figure 2 indicate the presence of this phenomenon with the overall decreasing trend for haze in both PDLCs for curing at all three levels and eventual stabilization within two weeks.

However, the trend for haze as a function of increasing UV energy for the two specimens are different. Specifically, the haze value of P025-40 decreases, but that of P025-49.5 PDLC increases with the UV energy. The opposite trends are observed for LC droplet dimensions in the two PDLC specimens (see Table 2). At the highest UV energy employed $\left(1268 \mathrm{~mJ} / \mathrm{cm}^{2}\right)$, the PS and matrix curing are nearer to completion, and the stabilized haze value of the P025-40 film is around $2 \%$ lower than that of the P025-49.5 film. The decreasing haze trend for both PDLC systems is a clear indication of the purification of LC micro-droplets by diffusion of the LCs and the greater extent of curing of the pre-polymer matrix, which results in more excellent index matching.

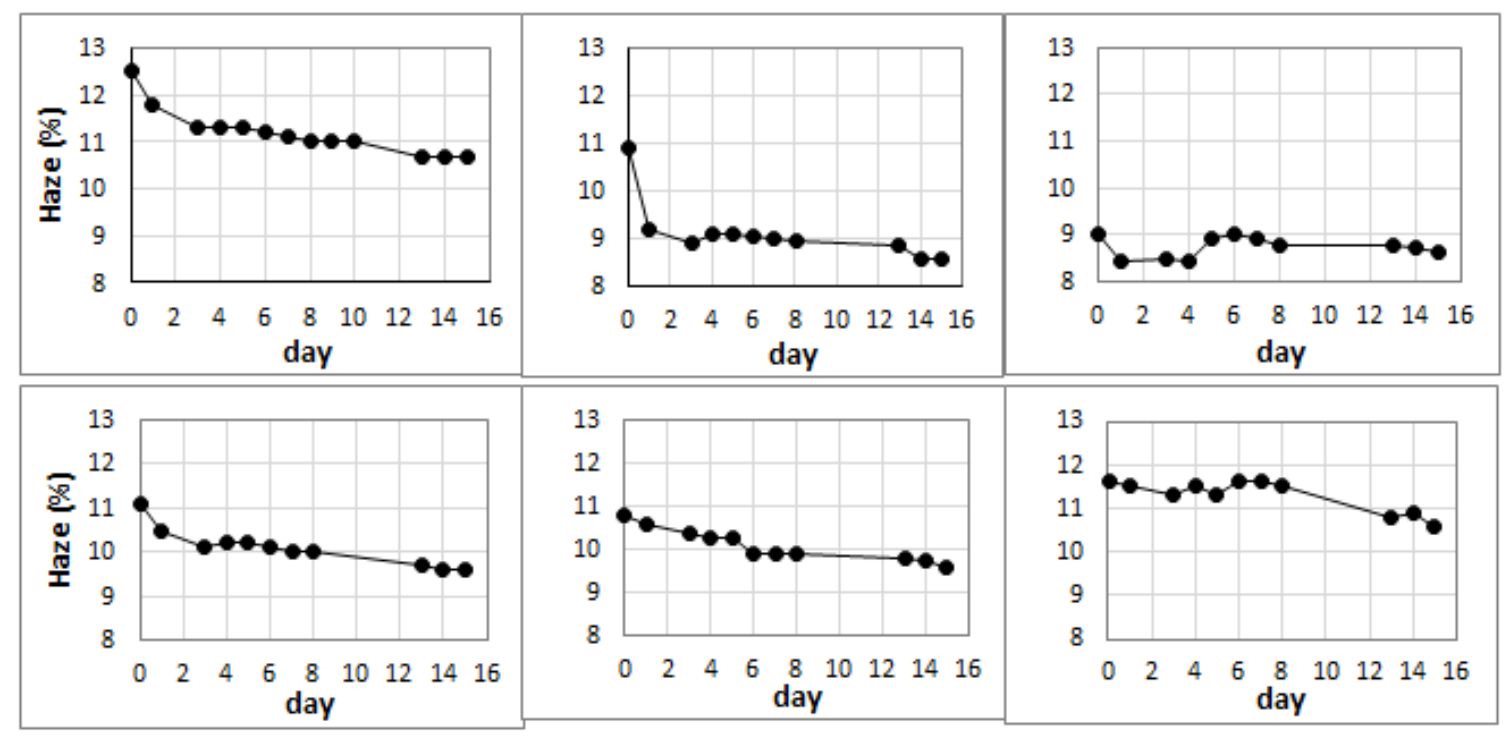

Figure 2 Time variation of Haze in P025-40 (top) and P025-49.5 (bottom) PDLC films at 38.2 (left), 74.4 and 126.8 (right) $\mathrm{mJ} / \mathrm{cm}^{2}$.

Figures 3 and 4, respectively, show Tmax and Tmin of P025-PDLC specimens. In both PDLC specimens, when the UV curing intensity is $380 \mathrm{~mJ} / \mathrm{cm}^{2}, T_{\max }$ shows an initial increase, but when it is $1268 \mathrm{~mJ} / \mathrm{cm}^{2}$, it shows a decreasing trend. Further, Tmax stabilizes at $70 \%$ in both specimens. Further, as shown in Figure 4, for both PDLC specimens, Tmin decreases with increasing UV energy values. The initial trend of increase with time at the lowest UV energy $\left(380 \mathrm{~mJ} / \mathrm{cm}^{2}\right)$ is similar to the trend displayed by $T_{\max }$, but at higher energy levels, $T_{\min }$ is almost independent of time. Further, the stabilized value of Tmin for the P025-40 film (2.8\%) is higher than that for the P02549.5 (2.4\%). Although further analysis of the data is beyond the scope of this study, it is clear that the existence of the transient phenomenon in relation to the optical transmissions is also the outcome of the time dependency of the LC droplet purification and relative matrix during the aging of PDLC films. 


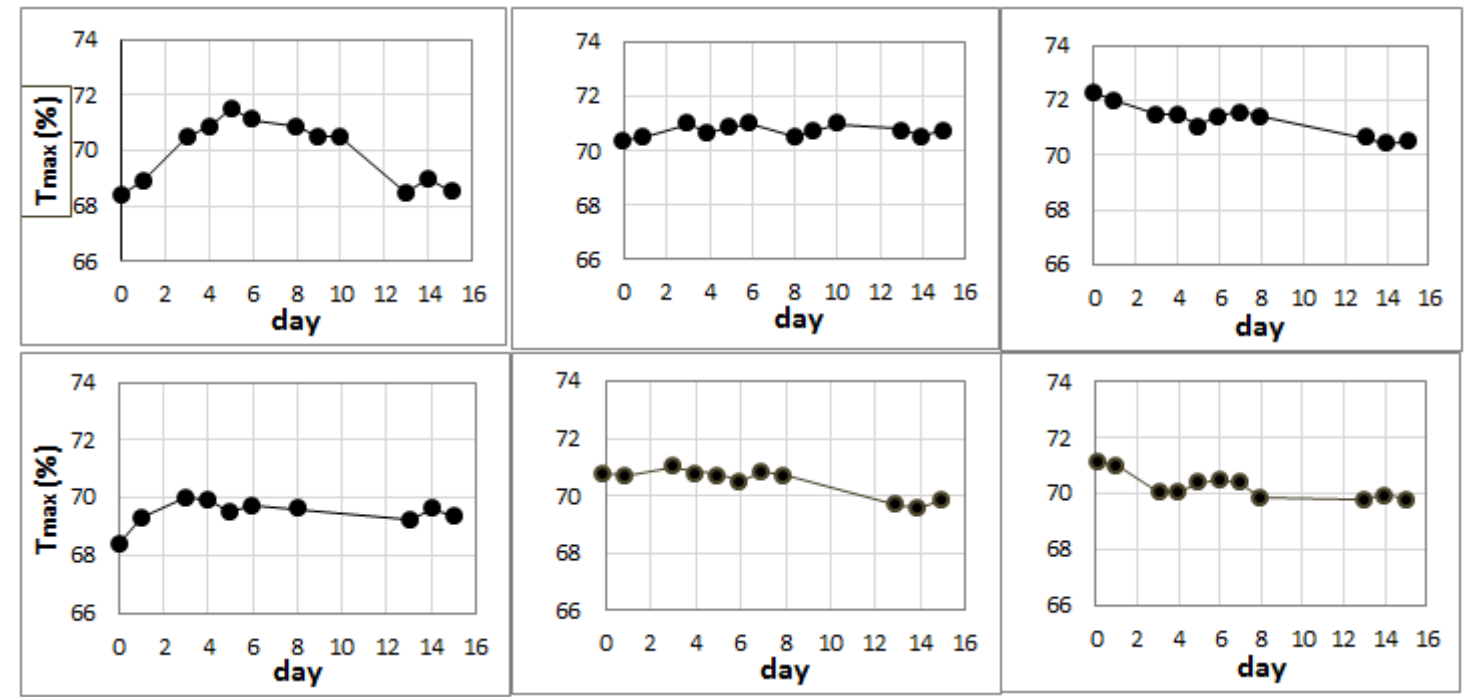

Figure 3 Time variation of Tmax in P025-40 (top) 7 P025-49.5 (bottom) PDLCs at 380 (left), 634 (center) and 1268 (right) $\mathrm{mJ} / \mathrm{cm}^{2}$.
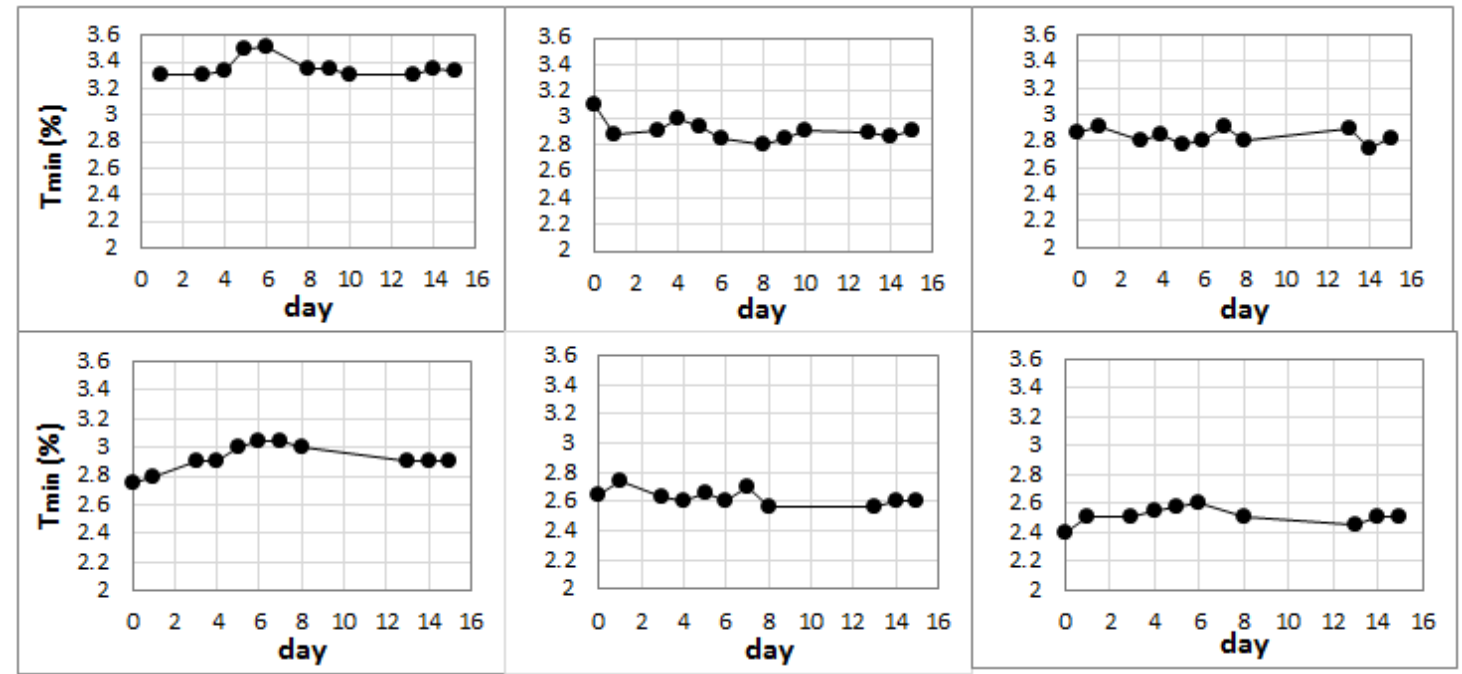

Figure 4 Time variation of $T_{\min }$ in P025-40 (top) \& P025-49.5 (bottom) PDLCs at 380 (left), 634 (center) and 1268 (right) $\mathrm{mJ} / \mathrm{cm}^{2}$.

\subsection{Transient Phenomenon in Terms of Operating Voltage}

The transient phenomenon in terms of $\mathrm{V}_{10}$ and $\mathrm{V}_{90}$ of P025-40 and P025-49.9 PDLC films as a function of the UV curing energy is presented in Figures 5 and 6, respectively. As shown in Figure 5, the time dependency of $\mathrm{V}_{10}$ as a function of the UV energy shows a distinct decreasing trend, before stabilization. However, the overall magnitude of $V_{10}$ for P025-40 is 5-7 V larger than that for P025-49.5, at both the initial and stabilization instances. As shown in Figure 6, we also observe similar trends for V90 for different UV energies in both PDLC film specimens: V90 also exhibits a decrease with both time and UV energy. The stabilized $\mathrm{V} 90$ values decrease by $15 \mathrm{~V}$ in P025-40 and by $10 \mathrm{~V}$ in P025-49.5 PDLC films. After stabilization, the overall decrease in V90 of P025-40 is $10 \mathrm{~V}$ larger than that of P025-49.5. Regardless of the controversy related to the morphology, the fact that $V_{10}$ and $V_{90}$ of P025-40 are higher than those of P025-49.5 can be attributed only to the 
relatively higher droplet anchoring energy in the former. The decreasing trend of voltage with time in both PDLCs is due to the decrease in the diffusion of the LC and pre-polymer components across the droplet boundaries. This phenomenon results in a decrease in the anchoring energy within LC droplets.

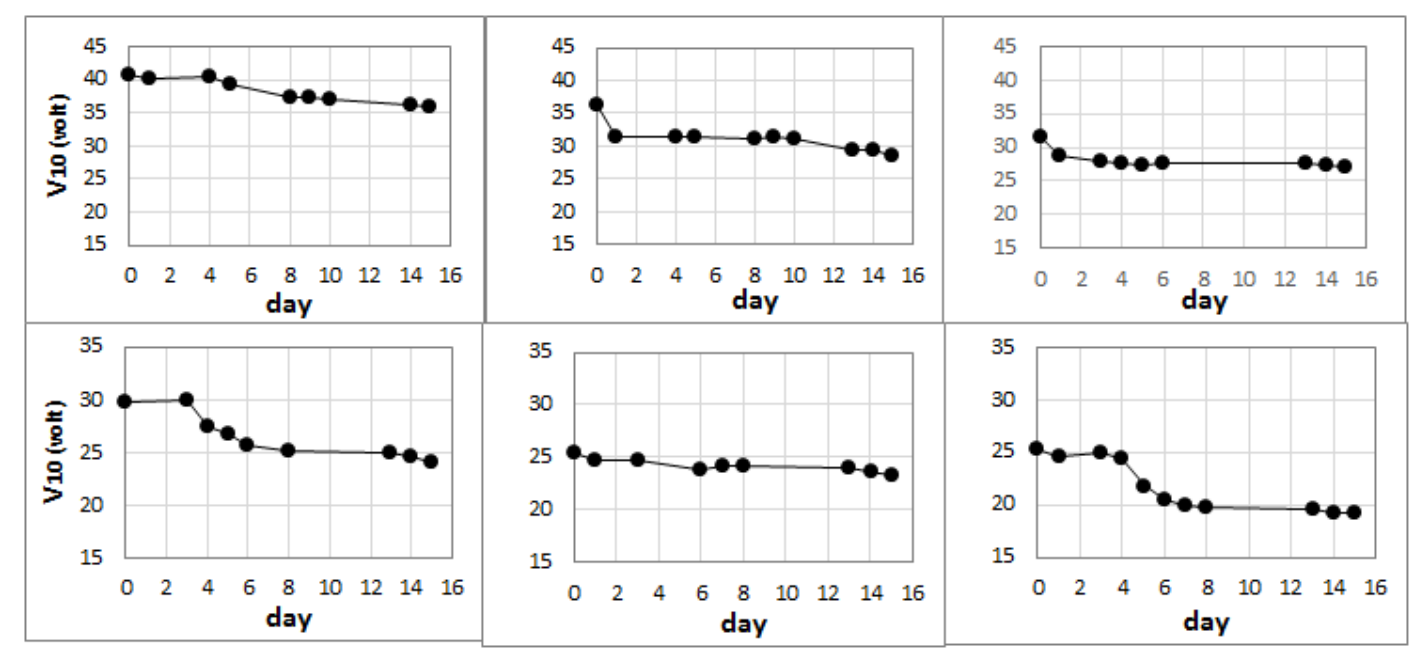

Figure 5 Time variation of $\mathrm{V}_{10}$ in P025-40 (top) \& P025-49.5 (bottom) PDLCs at 380 (left), 634 (center) and 1268 (right) $\mathrm{mJ} / \mathrm{cm}^{2}$.

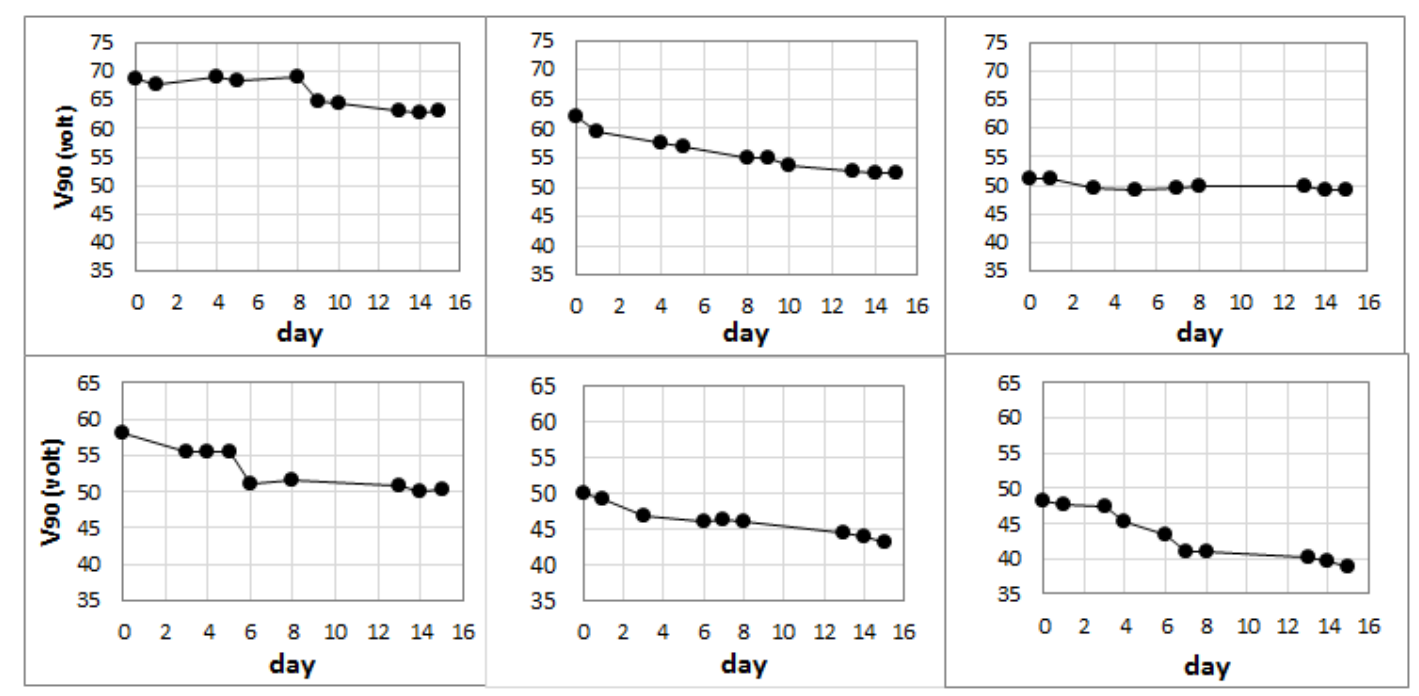

Figure 6 Time variation of $\mathrm{V}_{90}$ in P025-40 (top) \& P025-49.5 (bottom) PDLCs at 380 (left), 634 (center) and 1268 (right) $\mathrm{mJ} / \mathrm{cm}^{2}$.

According to the results in Figures 5 and 6, both P025-40 and P025-49.5 films show decreasing trends of $\mathrm{V}_{10}$ and $\mathrm{V}_{90}$ with increasing UV energy. This trend of P925-40 agrees with the decreasing trend of LC droplet sizes (see Table 2), which is also reported in the literature: larger LC droplets result in lower threshold and saturation voltages [20-24]. This is in contrast to the trend observed in the P025-49.5 film: the voltages decrease with decreasing LC droplet sizes. On the other hand, by increasing the UV curing energy, the LC droplets sizes usually decrease, which is the case in P025-49.5. However, we currently do not have any explanation about the cause of the increase in $<D>$ with the UV energy in P025-40. 


\subsection{Transient Phenomenon in Terms of Response Time}

The effects of time and UV energy on $\tau_{\text {on }}$ and $\tau_{\text {off }}$ of P025-40 and P025-49.5 PDLC films are plotted in Figures 7 and 8, respectively. As shown in Figure 7, $\tau_{\text {on }}$ for both PDLC specimens is independent of time, but it increases with the UV curing energy. With increasing UV energy, $\tau_{\text {on }}$ increases from 4 to $5 \mathrm{~ms}$ for P025-40 and from 4 to $11 \mathrm{~ms}$ for P025-49.5. Further, as shown in Figure $8, t_{\text {off }}$ increases to a greater extent with the UV energy in both PDLC film formulations. In the P025-40 film, with an increase in the UV energy, the value of the stabilized $t_{\text {off }}$ value increases by $16 \mathrm{~ms}$ (from 27 to $43 \mathrm{~ms}$ ), whereas in the P025-49.5 film, the stabilized $\tau_{\text {off }}$ value increases by $60 \mathrm{~ms}$ (from 40 to $100 \mathrm{~ms}$ ). The increasing trend of response times with increasing UV energy generally correlates to decreasing droplet sizes [20-22]. This correlation is compatible with the results for P025-49.5: $\angle D>$ decreases from 0.63 to $0.52 \mathrm{~mm}$. However, it is incompatible with the results for P025-40: $<D>$ increases from 0.33 to $0.71 \mathrm{~mm}$ (Figure 1).

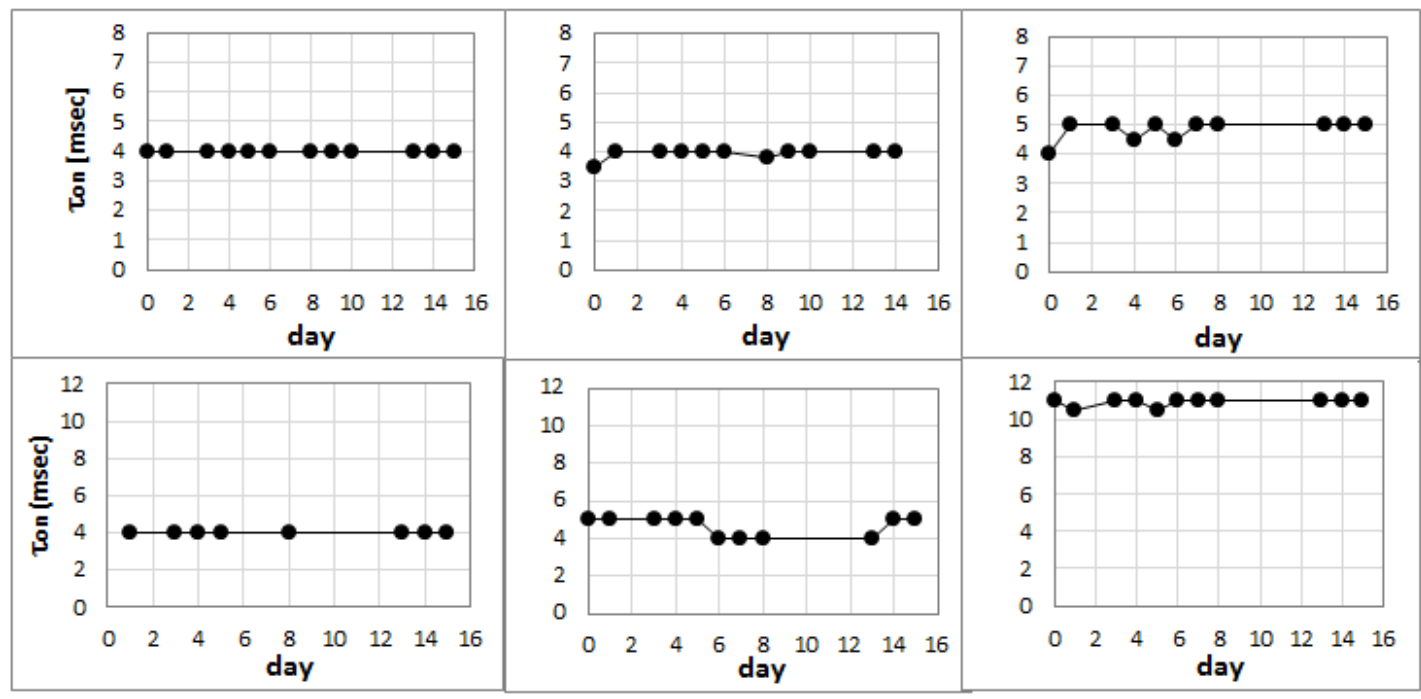

Figure 7 Time variation of $\tau_{\text {on }}$ in P025-40 (top) \& P025-49.5 (bottom) PDLC films at 380 (left), 634 (center) and 1268 (right) $\mathrm{mJ} / \mathrm{cm}^{2}$.

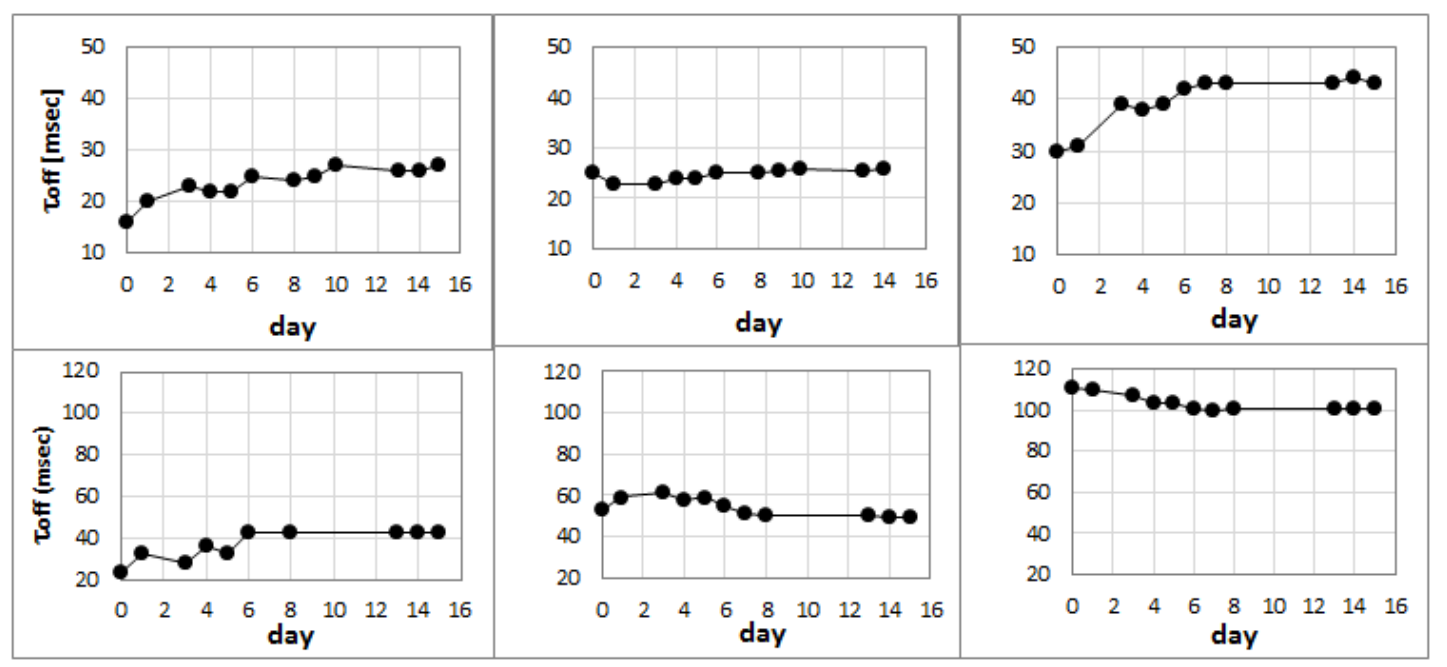

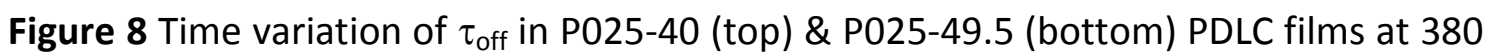
(left), 634 (center) and 1268 (right) $\mathrm{mJ} / \mathrm{cm}^{2}$. 


\section{Conclusion}

In the present study, we confirm the existence of the transient phenomenon, i.e., the temporal variation and subsequent stabilization of electro-optical properties of as-made PDLC films fabricated using the phase separation method. The study of this phenomenon is essential in industrial manufacturing, quality control, and technical documentation of products. This work is part of our ongoing study on the subject; herein, we provide the first experimental evidence of the transient phenomenon in PDLCs.

Although we are studying various PDLC formulations at different process conditions, in this work, we present the transient phenomenon observed in two PDLC formulations: the results indicate that the electro-optical properties (haze, $T_{\max }, T_{\min }, V_{10}, V_{90}, \tau_{\text {on }}$ and $\tau_{\text {off }}$ ) confirm the transient phenomenon within two weeks for different UV curing energies. All electro-optical

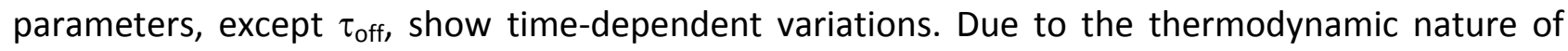
phase separation, the studied PDLC formulations remain dynamic systems after preparation because although the matrix curing is almost complete, a substantial amount of LCs remains in the matrix as the plasticizer. Therefore, it is a rational expectation that some or all electro-optical properties of the UV-cured PDLC film prepared by phase separation methods are expected to change with time.

Consequently, it is expected that this temporal effect, which we referred to as the "transient phenomenon," would exist as long as curing of the matrix is not complete and diffusion of LC and pre-polymer components occurs across the LC droplet boundaries. In general, the time dependency of PDLC electro-optical properties depends on many material properties and process conditions, and although understanding all these factors is beyond the scope of the present study, they are the subject of our ongoing studies, which will be reported in the future.

\section{Author Contributions}

Khenin and Tamari have conducted the experimental parts; Hakemi and Gal-Fuss have contributed to writing, completion and submission of the article.

\section{Competing Interests}

The authors have declared that no competing interests exist.

\section{References}

1. Fergason JL. Encapsulated liquid crystal and method. US Patent 4435047A, 1984.

2. Doane JW, Chidichimo G, Vaz N. US patent 4688900 \& 4671618, 1987.

3. Drzaic PS. Liquid crystal dispersions. Singapore: World Scientific; 1995.

4. Bouteiller L, Le Barny P. Polymer-dispersed liquid crystals: Preparation, operation and application. Liq Cryst. 1996; 21: 157-174.

5. Cheng SX, Bai RK, Zou YF, Pan CY. Electro-optical properties of polymer dispersed liquid crystal materials. J Appl Phys. 1996; 80: 1991-1995.

6. Hakemi H. Industrial development of plastic PDLC: Is there a future? Liq Cryst Today. 1998; 8: 7-12. 
7. Crawford GP, Firehammer JA, Lawandy NM. Image mode projection using TN and PDLC displays. Mol Cryst Liq Cryst. 2000; 351: 35-42.

8. Hoppe CE, Galante MJ, Oyanguren PA, Williams RJJ. Polymer-dispersed liquid crystals with cocontinuous structures generated by polymerization-induced phase separation of EBBA-epoxy solutions. Macromolecules. 2002; 35: 6324-6331.

9. Klosowicz SJ, Aleksander M. Effect of polymer-dispersed liquid crystal morphology on its optical performance. Opto-Electronics Rev. 2004; 12: 305-312.

10. Hoppe CE, Galante MJ, Oyanguren PA, Williams RJJ. Optical properties of novel thermally switched PDLC films composed of a liquid crystal distributed in a thermoplastic/thermoset polymer blend. Mater Sci Eng. 2004; 24: 591-594.

11. Drzaic P, Drzaic PS. Putting liquid crystal droplets to work: A short history of polymer dispersed liquid crystals. Liq Cryst. 2006; 33: 1281-1285.

12. Ahmad F, Jamil M, Jeon YJ, Woo L, Jung JE, Jang JE. Investigation of nonionic diazo dye-doped polymer dispersed liquid crystal film. Bull Mater Sci. 2012; 35: 221-231.

13. Liu ZS, Xu LP, Liang XD, Wang ZH, Zhang HM. Preparation and performance testing of flexible PDLC films. Adv Mater Res. 2014; 1015: 89-92.

14. Ellahi M, Rafique, MY. Electro-optical properties of PDLC films using diethylenetriamine (DETA) hardener. Mol Cryst Liq Cryst. 2016; 638: 103-110.

15. Hakemi H. Polymer-dispersed liquid crystal technology "industrial evolution and current market situation". Liq Cryst Today. 2017; 26: 70-73.

16. Hakemi $\mathrm{H}$. The effect of thickness on morphology and electro-optics of plastic thermoset polymer dispersed liquid crystal (PDLC). Mol Cryst Liq Cryst. 2019; 681: 12-22.

17. Hakemi H, Pinshow O, Gal-Fuss D. Evaluation of polymer dispersed liquid crystal (PDLC) for passive rear projection screen application. RPM. 2019; 1: 15. doi:10.21926/rpm.1903002.

18. Nolan P, Tillin M, Coates D. Liquid crystal microdroplet composition in a UV cured PDLC film. Mol Cryst Liq Cryst Letters. 1992; 8: 129-135.

19. Malik MK, Bhatia PG, Deshmukh RR. Effect of nematic liquid crystals on optical properties of solvent induced phase separated PDLC composite films. Indian J Sci Technol. 2012; 5: 34403452.

20. Henry RM, Ramsey RA, Sharma SC. Effects of crosslinking agent, cure temperature, and UV flux on the electro-optical properties of polymer-dispersed liquid crystal cells. J Polym Sci Part B: Polym Phys. 2004; 42: 404-410.

21. De Sarkara M, Qi J, Crawford GP. Influence of partial matrix fluorination on morphology and performance of HPDLC transmission gratings. Polymer. 2002; 43: 7335-7344.

22. Koo JJ, No YS, Jeon CW, Kim JH. Improvement of electro-optic properties in PDLC device by using new cross-linker for the control of the contrast ratio, response time and driving voltage. Mol Cryst Liq Cryst. 2008; 491: 58-66.

23. Yamaguchi R, Sudo N, Sato S. Effects of UV irradiation in memory-type PDLC films formed by a photo-induced phase separation. Mol Cryst Liq Cryst. 1995; 262: 119-127.

24. Carter SA, Le Grange JD, White W, Boo J, Wiltzius P. Dependence of the morphology of polymer dispersed liquid crystals on the UV polymerization process. J Appl Phys. 1997; 81: 5992. 


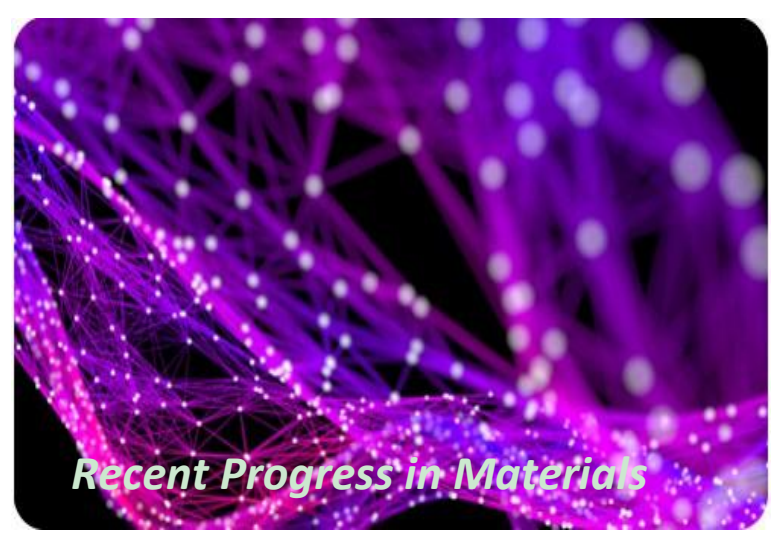

Enjoy Recent Progress in Materials by:

1. Submitting a manuscript

2. Joining in volunteer reviewer bank

3. Joining Editorial Board

4. Guest editing a special issue

For more details, please visit:

http://www.lidsen.com/journals/rpm 